\title{
Michael B. Frisch: A Career in Positive Psychology and Well-Being Assessment and Intervention
}

\author{
Michael B. Frisch ${ }^{1}$
}

Received: 23 September 2015 / Accepted: 27 July 2016 / Published online: 23 August 2016 (C) Springer Science+Business Media Dordrecht and The International Society for Quality-of-Life Studies (ISQOLS) 2016

It can be interesting to see the route taken by academics. My academic journey began with an inspiring Catholic education in Milwaukee, Wisconsin, USA. The individual attention of my teachers, including Catholic nuns, nurtured and diverted me from a poor and troubled home and gave me an identity as one skilled in and in love with learning. I received a real taste of college from my Jesuit teachers, many with two or three advanced degrees themselves, at Marquette University High School where I waited on tables and worked the switchboard at the Jesuit priest residence as part of my scholarship. Like other resilient children, I used my outgoing personality, work ethic, and love of people to find mentors, friends, and supporters throughout my life.

Short of graduate students to teach classes, the psychology department at my undergraduate alma mater, the University of Wisconsin at Milwaukee, nurtured and hired me to teach Research Methods as I sat in on graduate classes in statistics. I studied evenings without distraction as part of my night-watchman job at the Milwaukee Red Cross where I served as a volunteer, eventually becoming the youngest person in history to serve on the American Red Cross' National Board of Govenors. Raymond L. Higgins patiently taught me how to design and write up research projects en route to my Ph.D. at the University of Kansas' Department of Psychology, a very exciting place to be in the mid- to late 1970's.

As a graduate student and young academic, I tried to keep up with journal articles and abstracts both in and outside my field of clinical psychology. A few of these related to well-being, contentment, and happiness. Inspired as an undergraduate by Thomas Stampfl's example and his exhortation to apply experimental findings from all areas of psychology to the clinical (and coaching) enterprise, I began in 1980 to apply ideas and findings from the fields of subjective well-being and social indicators to the assessment

Michael B. Frisch

frisch@baylor.edu

1 Department of Psychology and Neuroscience, Baylor University, Waco, TX 76798, USA 
and promotion of positive experience and functioning in mental health care and beyond. Despite discouraging words from some, I persevered, developing an evidence-based and research supported well-being assessment, the Quality of Life Inventory or QOLI Frisch et al. (2005), and a comprehensive, evidence-based approach to positive psychology/well-being intervention called Quality of Life Therapy (Frisch 2013). In spite of the naysayers, the top two psychological assessment companies competed to license and market my Quality of Life Inventory to practicing psychologists and health care professionals. Eminent psychologists such as Alan Kazdin and Ed Diener encouraged my work. James R. Rodrigue secured USA NIH grants to conduct successful randomized controlled trials in which Quality of Life Therapy was favorably compared with existing treatments and interventions. In an effort to bring well-being interventions to new and underserved parts of the world, indigenous researchers and myself, are just now completing a randomized trial of my approach to treat heart disease and the women of Iran. As an academic, I was touched and heartened by Robert Furey's (2007) review of my book for conducting Quality of Life Therapy entitled Quality of Life Therapy, stating: "This author is a disciplined researcher and a passionate clinician. He is also a fervent educator" (Positive Mentoring, para. 4). This is just the epitaph I would like for my career!

Both the QOLI and QOLT predate the advent of positive psychology in 1998, prompting Ed Diener to comment that Frisch studied positive psychology and wellbeing long before "it was cool" to do so. Ed Diener successfully nominated me to be a Research Fellow in the International Society for Quality of Life Studies. I am also a Founding Fellow in Aaron T. Beck's Academy of Cognitive Therapy and a past Director of Clinical Training in Baylor University's APA-approved doctoral program in clinical psychology. None of these accomplishments could have happened without the wonderful friendship, support, and constructive criticism of colleagues, including Alan E. Kazdin, Ed Diener, M. Joseph Sirgy, Raymond L. Higgins, Robin B. Jarrett, A. John Rush, Alex C. Michalos, Ruut Veenhoven, Hans H. Strupp, John Flanagan, Lynn Rehm, Kenneth C. Land, C. R. Snyder, and Aaron T. Beck. "We do (or accomplish) nothing alone", as my friend, the late Bernard Rapoport used to say.

I am also deeply grateful to my clinical and coaching clients, students, and supervisees who helped me to hone and test my ideas and techniques. Baylor University provided the perfect venue for me to teach graduate and undergraduate students, research happiness and depression in a broad and interdisciplinary way, supervise doctoral students in therapy and research, and see clients in my office at the university. Such places and positions are rare, as Ruut Veenhoven can attest; working at Baylor gave me a once in a lifetime opportunity. Finally, the encouragement and support of the International Society for Quality of Life Studies under Joe Sirgy's leadership made my career flourish and thrive.

\section{References}

Frisch, M. B. (2013). Evidence-Based Well-Being/Positive Psychology Assessment and Intervention with Quality of Life Therapy and Coaching and the Quality of Life Inventory (QOLI). Social Indicators Research, 114, 193-227. doi:10.1007/s11205-012-0140-7. 
Frisch, M. B., Clark, M. P., Rouse, S. V., Rudd, M. D., Paweleck, J., \& Greenstone, A. (2005). Predictive and treatment validity of life satisfaction and the Quality of Life Inventory. Assessment, 12(1), 66-78. doi:10. $1177 / 1073191104268006$.

Furey, R. (2007). Beyond Feeling Better: Adding Happiness to the Treatment Plan. Psyccritiques, 52(5). doi: 10.1037/a0006300. 